\title{
Research Paper Application of ranked-set sampling in estimation of average yield of cotton crop
}

\section{- Animesh Kumar, Pramod Kumar Moury, Md. Asif Khan, Sonica Priyadarshini, Rajeev Kumar and Himanshushekhar Chaurasia}

See end of the paper for authors' affiliations

Correspondence to :

Pramod Kumar Moury

ICAR-Indian Agricultural Statistics Research Institute, Library Avenue, Pusa, New Delhi, India

Email: pramodmaurya.stat @gmail.com

Paper History :

Received : 13.01.2020;

Revised : 08.02.2020;

Accepted : 15.02 .2020
ABSTRACT : When actual measurements of sampling units are tedious, time taking or expensive in terms of money or time then the use of the ranked set sampling (RSS) may yields a more precise estimator of population mean than simple random sampling (SRS). In this study, the method developed by Ozturk and Kavlak (2018) based on ranked set sampling approach has been applied for estimation of yield ( $\mathrm{kg} / \mathrm{ha}$ ) of cotton crop and compared with that of SRS methodology using the crop cutting experiments (CCE) data pertaining to four districts in which each two of these district belongs to the Maharashtra and Andhra Pradesh states for the year 2012-13. A simulation study has also been conducted to validate the method developed by Ozturk and Kavlak (2018) that showed the RSS estimator perform better than SRS estimator even when the quality of ranking information in RSS sampling fluctuates. The result of the study has revealed that the model based on ranked set sampling provides better precision for estimate of average yield of cotton than SRS methodology.

KEY WORDS : Ranked set sampling, Model based RSS, Mean square prediction error, Concomitant ranking, Visual ranking

HOW TO CITE THIS PAPER : Kumar, Animesh, Moury, Pramod Kumar, Khan, Md. Asif, Priyadarshini, Sonica, Kumar, Rajeev and Chaurasia, Himanshushekhar (2020). Application of ranked-set sampling in estimation of average yield of cotton crop. Internat. Res. J. Agric. Eco. \& Stat., 11 (1) : 49-54, DOI : 10.15740/HAS/ IRJAES/11.1/49-54. Copyright@2020:HindAgri-Horticultural Society. 